\title{
Superconducting Magnet Development Capability of the LLNL High Field Test Facility
}

February 1990

John R. Miller

Stewart Shen

Leonard T. Summers

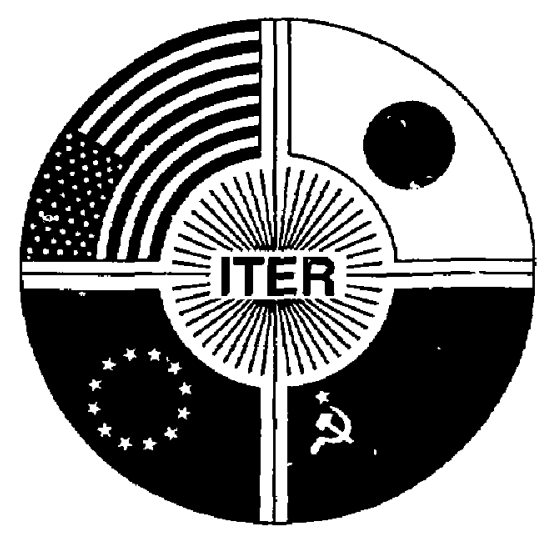

Lawrence Livermore National Laboratory

\section{MACTER}




\section{Contents}

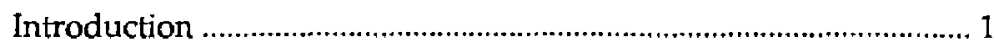

High-Field Test Facility Equipment at LLNL ............................... 3

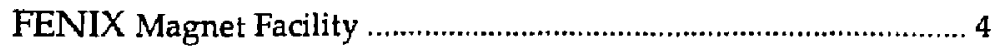

High-Field Test Facility (HFTF) 2-m Solenoid ................................ 6

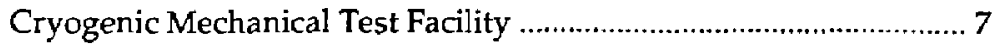

Electro-Mechanical Conductor Test Apparatus ….......................... 8

Electro-Mechanical Wire Test Apparatus........................................ 9

FENIX/HFTF Data System

and Network Topology .............................................................. 10

Helium Gas Management System (HGMS) .................................. 11

Airco Helium Liquefier / Refrigerator .......................................... 12

CTI 2800 Helium Liquefier......................................................, 13

MFTF-B/ITER Magnet Test Facility ......................................... 14

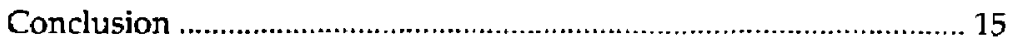




\section{Introduction}

The High-Field Test Facility (HFTF), located at Lawrence Livermore National Laboratory (LLNL), is uniquely capable of meeting testing requirements for development of the large-scale magnets for the international Thermonuclear Experimental Reactor (ITER). The centerpieces of this facility are the Fusion Engineering International Experimental (FENIX) Magnet Facility and the HFTF 2-m Solenoid Facility. Operated by LLNL's Superconducting Magnet Development Group (SCMDG), these and other supporting facilities of the HFTF are used by researchers for the development of cryogenic materials, large magnet components, and superconducting magnet systems.

The HFTF 2-m Solenoid Facility, now in operation, is a six-coil set with an axial entry test well. As presently configured, it can provide a uniform 11-T field over a sample volume approximately $0.32 \mathrm{~m}$ in diameter. Power supplies are available to deliver sample current up to $40 \mathrm{kA}$. Higher currents are possible by inductive means. An effective cryostat design allows continuous availability for testing in the 2-m Solenoid Facility for extended periods using a single helium liquefier. The facility was designed with separate magnet and test-well cryostats; therefore, rapid exchange of test articles is possible without disruption of the magnet's cryogenic environment. The 2-m Solenoid Facility, which has been in service since 1981, is scheduled for a major upgrade in 1991 that will increase the field to $15 \mathrm{~T}$ in a $0.36-\mathrm{m}$-diameter volume.

The FENIX Magnet Facility, which is presently under construction, will be fully operational in late 1990. It is a split-solenoid configuration that will provide experimenters with radial access to transverse magnetic fields up to $14 \mathrm{~T}$ in a uniform high-field region approximately $0.4 \mathrm{~m}$ in length. The access gap between solenoid halves is variable, but the initial setup will include a cryogenically isolated test well with a $100 \mathrm{~mm} \times 150 \mathrm{~mm}$ cross-section in the high-field region. Sample currents as high as $40 \mathrm{kA}$ are possible, using power supplies that are presently available. The thermally isolated sample test well allows rapid specimen change-out and independent control of the sample temperature during tests.
Also supporting the development of large-scale conductors and coil components, the HFTF has a number of other unique facilities for the characterization of cryogenic materials and components. For example, magnet structural alloys and insulations can be mechanically tesied at temperatures down to $4.2 \mathrm{~K}$; and small superconducting-magnet test stiunds allow characterization of superconducting wires, cables, and suksized conductors at fields up to $15 \mathrm{~T}$ and $12 \mathrm{kA}$ of current. Wires, cables, and conductors can be tested using hybrid electro-mechanical test facilities that can simultaneously 
apply high-field (15-T), high-current, longitudinal (200 kN), and/or transverse $(100 \mathrm{kN})$ loads. Heat-treatment and metallurgical-characterization facilities are available.

Both the large magnet systems and the materials test facilities are supported by a multi-channel data acquisition and analysis system. This system, comprising HP-330 and 360 computers and HP-3852 data acquisition units, provides real-time data display and control but is also integrated with the LLL VAX 8600 and the Cray machines of the MFENET for effective data manipulation, analysis, and transport.

All cryogenic test stands and liquefier/refrigerators in the HFTF are supported by an automated Helium Gas Management System (HGMS) that manages the recovery, purification, storage, and delivery of helium to various parts of the facility. To provide for possibly large refrigeration needs of future projects, $3-\mathrm{kW}$ and $8-\mathrm{kW}$ units at the nearby MFTF-B facility can, in principle, be made available. Large cryostats/vacuum vessels exist on site, including the $2-$ and 4- $\mathrm{m}$-diameter vessels that house the 2-m Solenoid and FENIX, respectively, and the end-cell sections of the MFTF-B vacuum vessel.

Details of LLNL's magnet development facilities are described in the following pages. For further systems specifications and equipment availability, contact Dr. J.R. Miller (415) $422-0679$ or Dr. S.S. Shen (415) 423-4826, Lawrence Livermore National Laboratory, P.O. Box 5511, L-643, Livermore, CA 94551, USA. 


\section{High-Field Test Facility Equipment at LLNL}

\section{Large Magnet Test Facilities}

FENIX Magnet Facility

High-Field Test Facility (HFTF) 2-m Solenoid

\section{Component and Materials}

Research and Development

Cryogenic Mechanical Test Facility

Electro-Mechanical Test Conductor Apparatus

Electro-Mechanical Wire Test Apparatus

\section{Supporting Technologies}

High-speed, multi-channel data acquisition and analysis system

VAX and National Magnetic Fusion Energy Computer Center

(NMFECC) Cray support for computation and data analysis

Semi-automatic Helium Gas Management System (HGMS)

Airco liquefier

CTI 2800 and 1400 liquefiers

3-kW and 8-kW MFTF-B liquefiers

2-m-diameter, 4-m-diameter, and MFTF-B cryostat/vacuum vessels for coil and conductor tests

Coil-winding equipment 


\section{FENIX Magnet Facility}

\section{General Description}

Magnet configuration: Two independent units, each comprising a $\mathrm{Nb}_{3} \mathrm{Sn}$ insert and a NbTi outsert. Each coil is separately encased.

Gap width: $100 \mathrm{~mm}$

High-field winding, i.d: $360 \mathrm{~mm}$

Uniform high-field region: $150-\mathrm{mm}$ diameter

Maximum field in test volume: $14.0 \mathrm{~T}$ (100-mm gap, iron cores)

Total cold mass: Approximately 75 tonnes

Total stored energy: Approximately $180 \mathrm{MJ}$

\section{Test Sample Information}

Configuration: Straight lengths or pancakes can be accommodated Sample inlet pressure: 0.5 to $3.0 \mathrm{MPa}$, adjustable Inlet temperature: 3.5 to $10 \mathrm{~K} ; 3.5 \mathrm{~K}$ by pumping on test well, $4.3 \mathrm{~K}$ using atmospheric test well, and higher temperatures using heater and bypass circuits Flow rate: $30 \mathrm{~g} \mathrm{~s}^{-1}$ total for all paths with $0.5 \mathrm{MPa}$ pressure at the test coil outlet-maximum flow is proportional to pressure Maximum sample current: $40 \mathrm{kA}$

Duty cycle: Continuous with $40-\mathrm{kA}$ conductors for several hours-helium supply supplemented using an existing $10-\mathrm{kL}$ dewar 


\section{FENIX Magnet Facility}

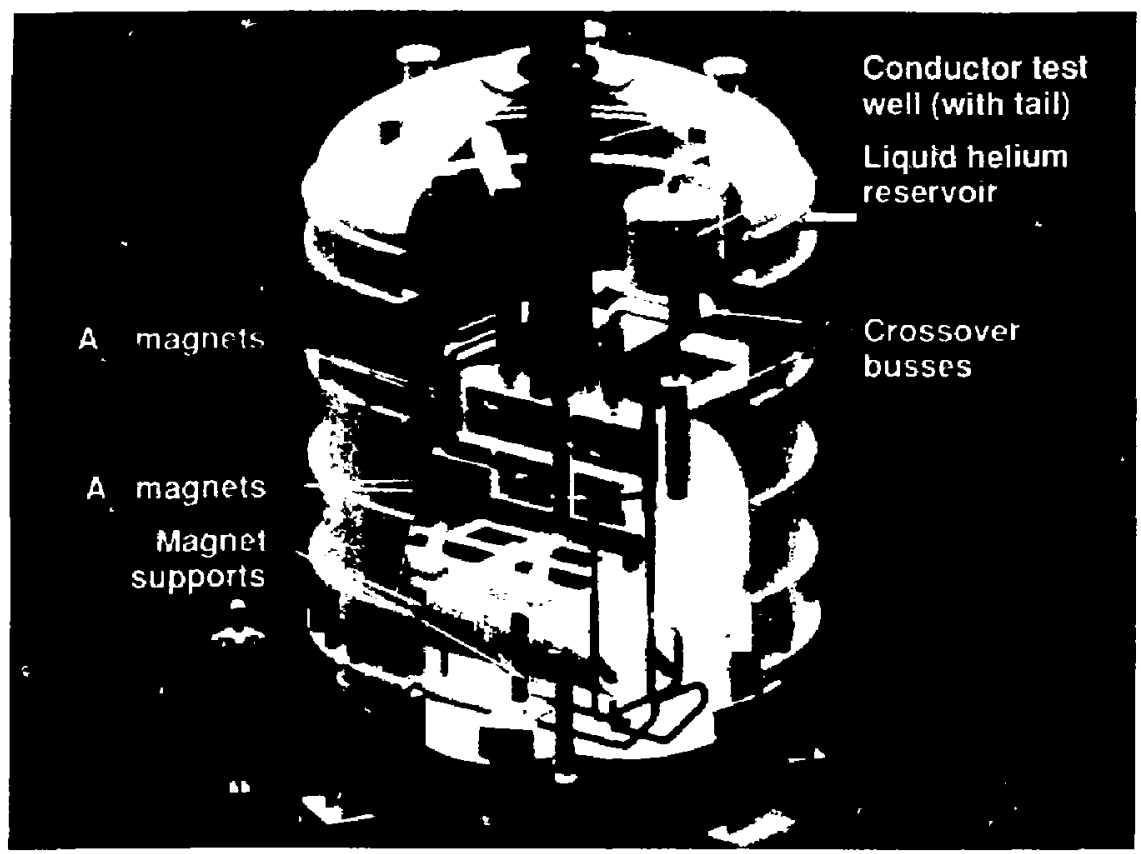

The Fusion Engineering International Experimental (FENIX) Magnet Facility, shown in the 4-m cryostat, is presently under construction. Planned to begin operation in the fall of 1990, FENIX will be capable of testing full-size ITER conductors. 


\section{High-Field Test Facility (HFTF) \\ 2-m Soleniod}

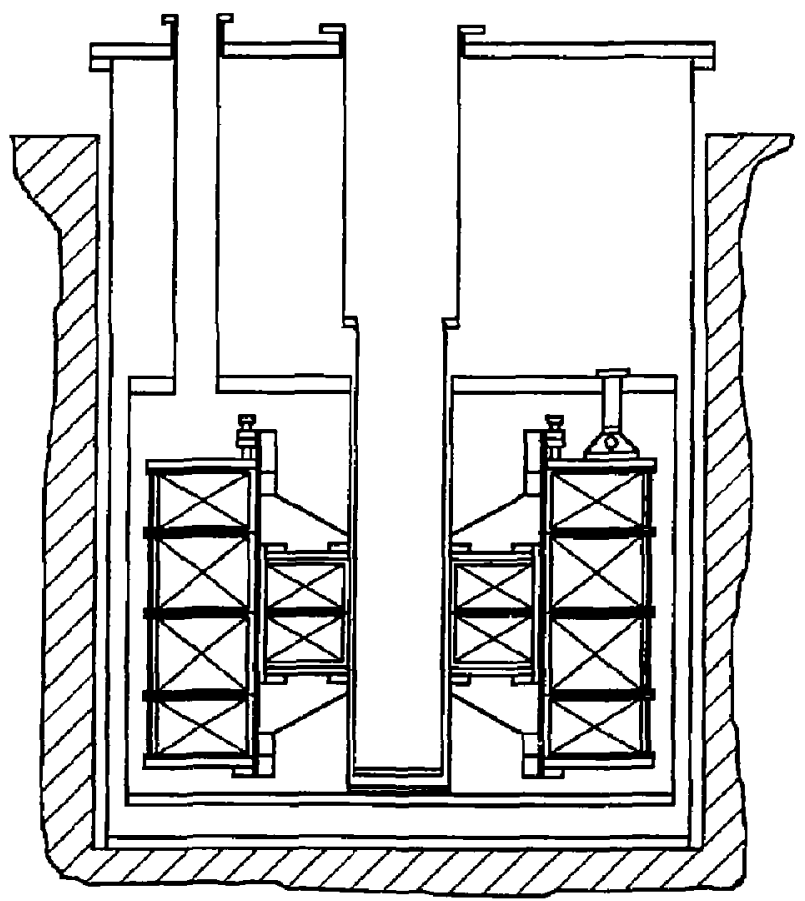

The High-Field Test Facility (HFTF) 2-m Solenoil provides a high backing field for testing large conductors, test coils, and magnets. The high-field capabilities of HFTF will be upgraded in 1991 with the addition of the Proof-of-Principal (PoP) coil to the magnet stack.

\section{NbTi Coils}

4

Winding i.d.

Winding o.d.

Operating current

Winding pack current density
4

$1.05 \mathrm{~m} \quad 0.4 \mathrm{~m}$

$1.71 \mathrm{~m} \quad 0.36 \mathrm{~m}$

$1.2 \mathrm{kA} \quad 5.0 \mathrm{kA}$

$32 \mathrm{~A} \mathrm{~mm}^{-2} 33 \mathrm{~A} \mathrm{~mm}^{-2}$

$B_{\max }=11 \mathrm{~T}$ (15 $\mathrm{T}$ with PoP coil upgrade)

Bore diameter $=36 \mathrm{~cm}$

Thermally isolated sample cryostat

Maximum sample current $=40 \mathrm{kA}$

$\mathrm{E}_{\text {stored }}=\mathrm{MJ}(57 \mathrm{MJ}$ with PoP coil) 


\section{Cryogenic Mechanical Test Facility}

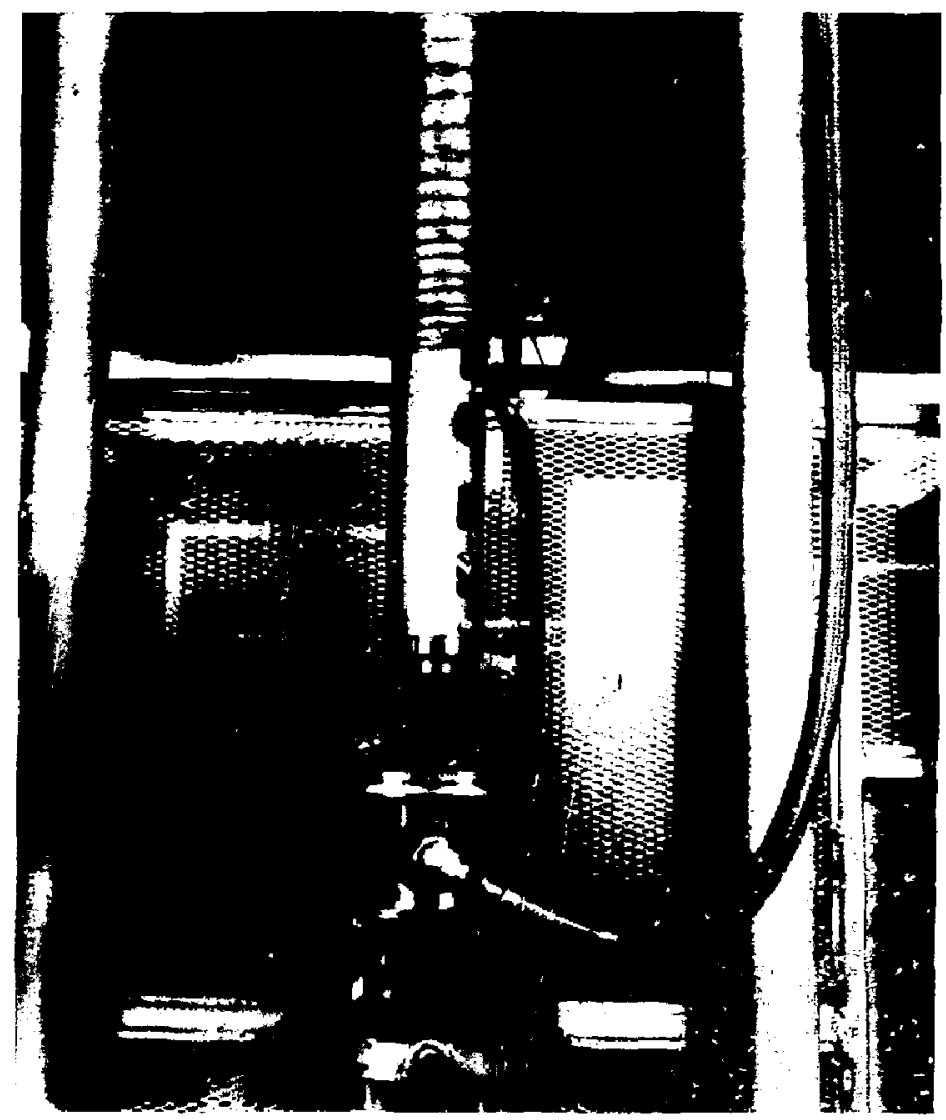

Mechanical testing of structural alloys and magnet insulation can be performed in this facility. This photo shows the lower end of the compression column where specimens are attached, and the upper portion of the sample cryostat.

- LHe, $\mathrm{LN}_{2}$, and room temperature operation

- Load, stroke, or strain control

- Loads to $100 \mathrm{kN}$

- Total stroke of $100 \mathrm{~mm}$

- Cyclic Joading with variable wave forms

- Accommodates the following ASTM specimen types

- Flat tensile

- Round tensile

- Compact Tension

- Highly efficient cryostat design for long-duration fatigue testing. 


\section{Electro-Mechanical Conductor Test Apparatus}

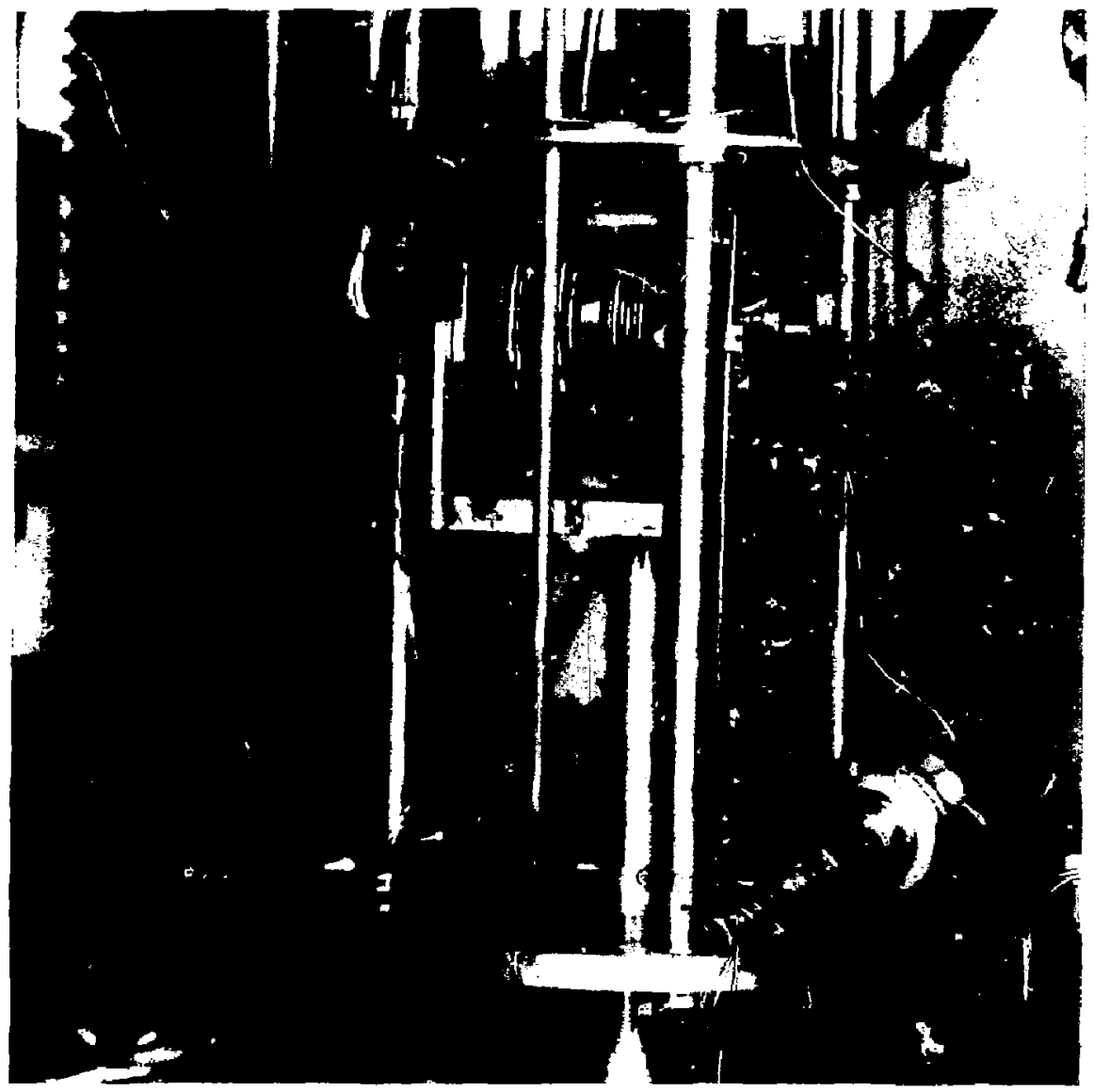

High fields, current, and both longitudinal and transverse loads can be individually or simultaneously applied to large $\mathrm{Nb}_{3} \mathrm{Sn}$ conductors.

- Load, stroke, or strain control for longitudinal tension

- Load control only for transverse compression

- Longitudinal tension to $200 \mathrm{kN}$

- Capable of cyclic loading with variable wave forms

- Sample lengths of $300 \mathrm{~mm}$ (50 mm in high field)

- Maximum sample cross section $10 \times 20 \mathrm{~mm}$

- Fields to $15 \mathrm{~T}$ (12.5 T for transverse load)

- Current to $12 \mathrm{kA}$ 


\section{Electro-Mechanical Wire Test Apparatus}

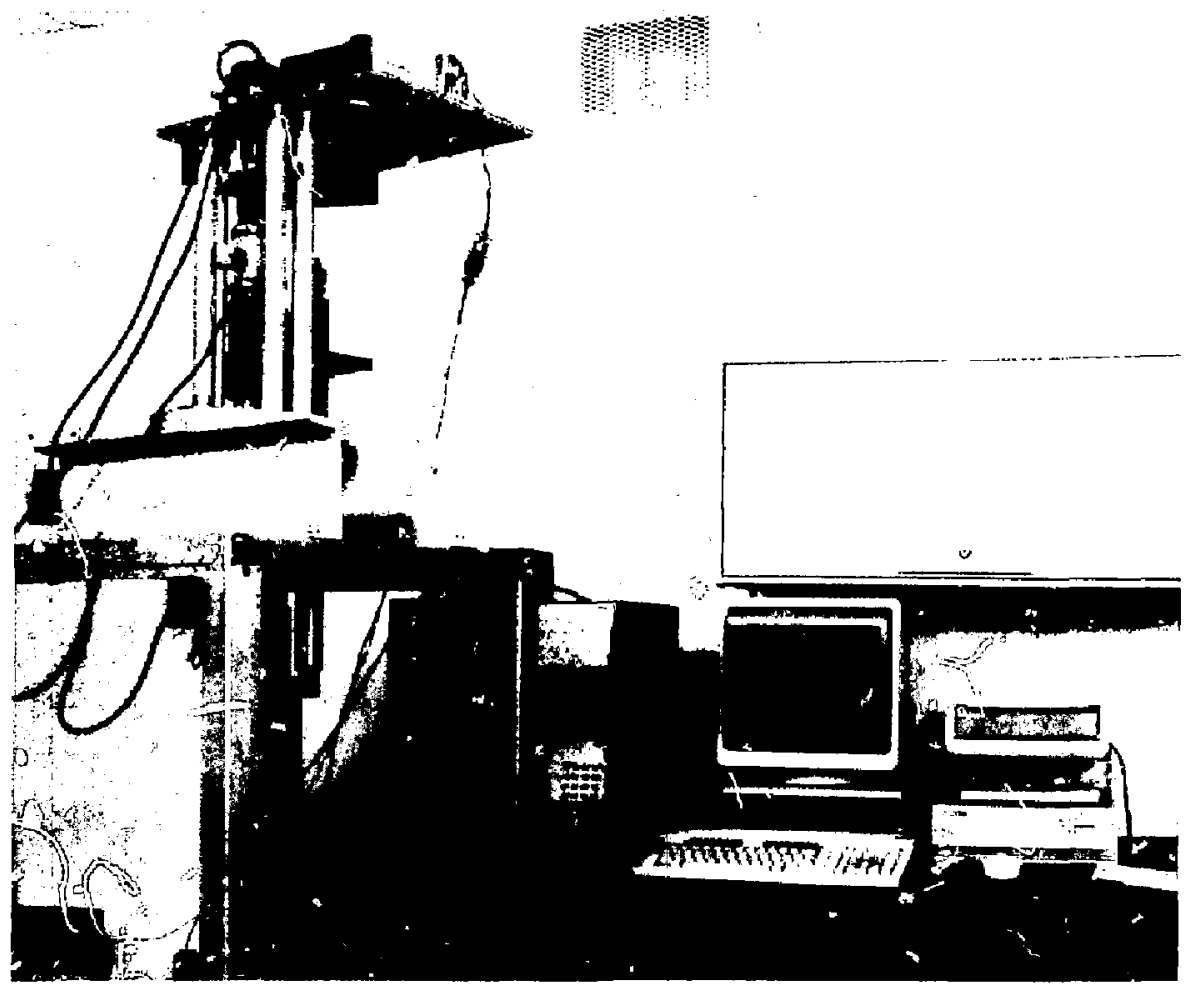

Electro-Mecha1 :cal Wire Test Apparatus for strain vs $J_{\mathcal{c}}$ tests and mechanical properties measurements of $\mathrm{NB}_{3} \mathrm{Sn}$ superconducting wires.

- Computer control and data acquisition us:ing an HP 9000 series 330

- Load or stroke control

- Luads to $2 \mathrm{kN}$

- 300-mm sample length with $50 \mathrm{~mm}$ in high field

- Current to $2 \mathrm{kA}$

- Fields to $15 \mathrm{~T}$ 


\section{FENIX/HFTF Data System and Network Topology}

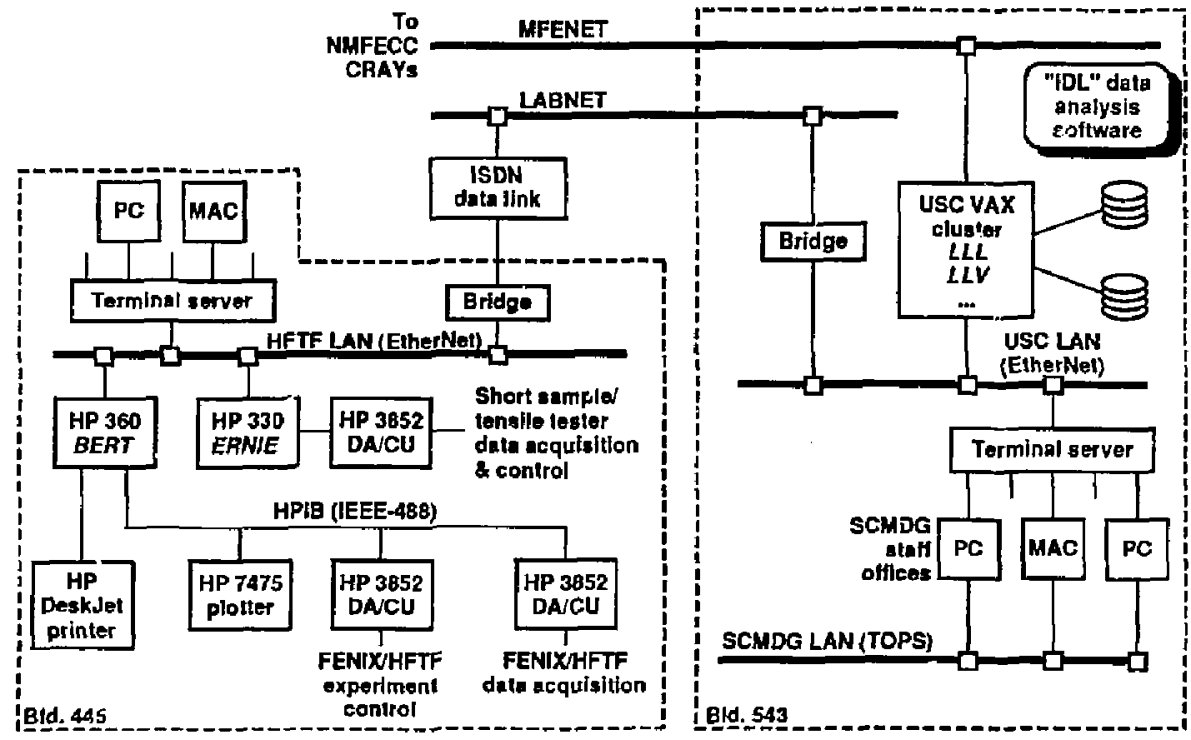

All experiments in the HFTF facility, including FENIX, are integrated with a computerized data acquisition and analysis system. Active experiment control and real-time data analysis are possible. The FENIX HFTF computers are networked to the NMFECC system.

\section{Dafa Acquisition and Analysis}

- Hewlett-Packard (HP) 360 computer with HP 3852 data acquisition units

- Analog inputs available for the sample fixture

(1) 20 channels, maximum sample rate $40 \mathrm{ch} / \mathrm{s}$,

$$
\text { 6-digit integrating voltmeter }
$$

(2) 50 channels, maximum sample rate $20,000 \mathrm{ch} / \mathrm{s}$,

13-bit analog/digital converter

- 20 Preston 8300 differential input isolation amplifiers,1000 $\mathrm{Vdc} \mathrm{cm}_{\mathrm{cm}}$. Gain: 1-1000, bandwidth: $1-1000 \mathrm{~Hz}$

- Several current sources available for transducer signal conditioninganging from $1 \mu \mathrm{A}$ to $50 \mathrm{~A}$.

- Real-time data displays and recorders during sample runs, with plotted raw data available after each run

- Data transferred to the LLL VAX 8600 for archiving in MDS database

- Data processing, analysis, and plotting with IDL software on the LLL VAX

- Data processing and analysis using the (NMFECC) Cray compriers 


\section{Helium Gas Management System (HGMS)}

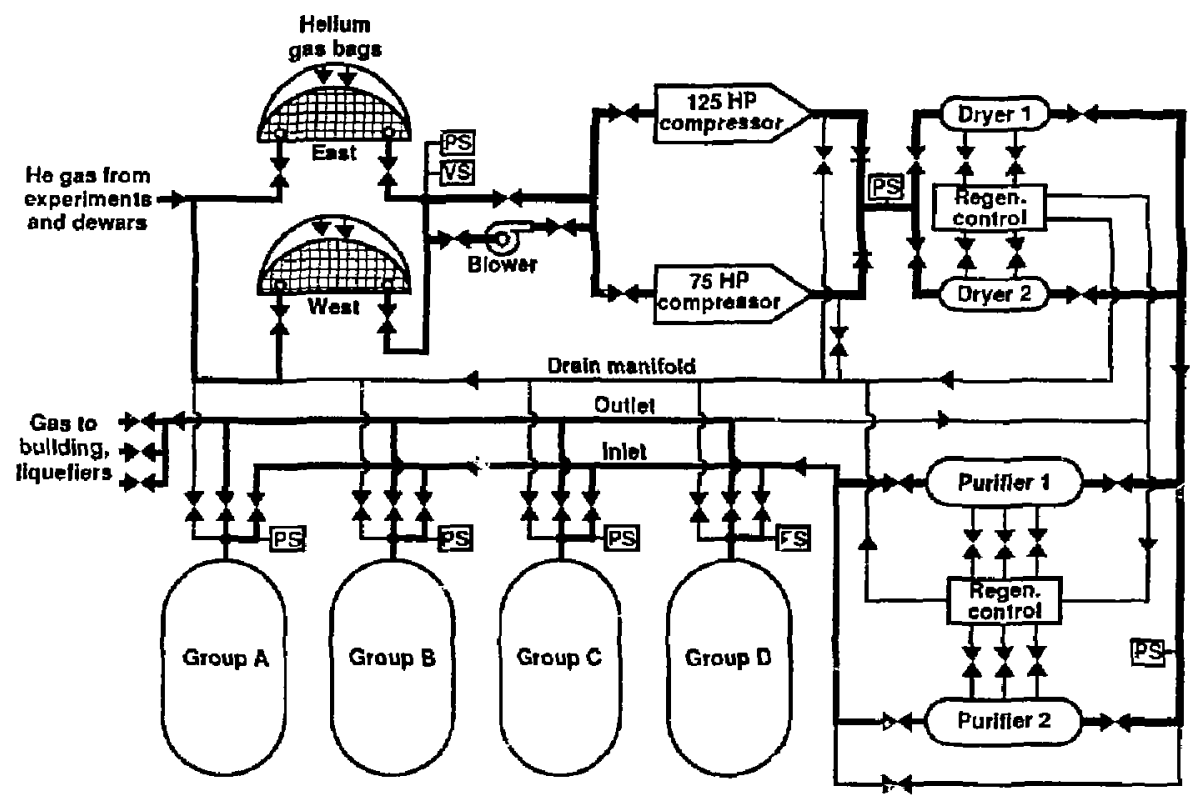

This semi-automated, closed-loop system provides liquid helium to all experiments through the liquefiers or by batch transfer from $10-\mathrm{kL}$ and $500-\mathrm{L}$ dewars. Boil-off gas is reprocessed for storage as gas for make-up supply to a variety of liquefiers.

- Hewlett-Packard computer and control interface

- Unattended operation, $24 \mathrm{hr} /$ day

- Processing speed: 630 equivalent liquid liters of helium gas per hour

- Outfut purity: <5 PPM total impurities

- Cryogen storage capaçities

- 19000 equivalent liquid liters helium as gas

-12000 liters of helium as liquid

-30000 liters of nitrogen as liquid 


\section{Airco Helium Liquefier/Refrigerator}

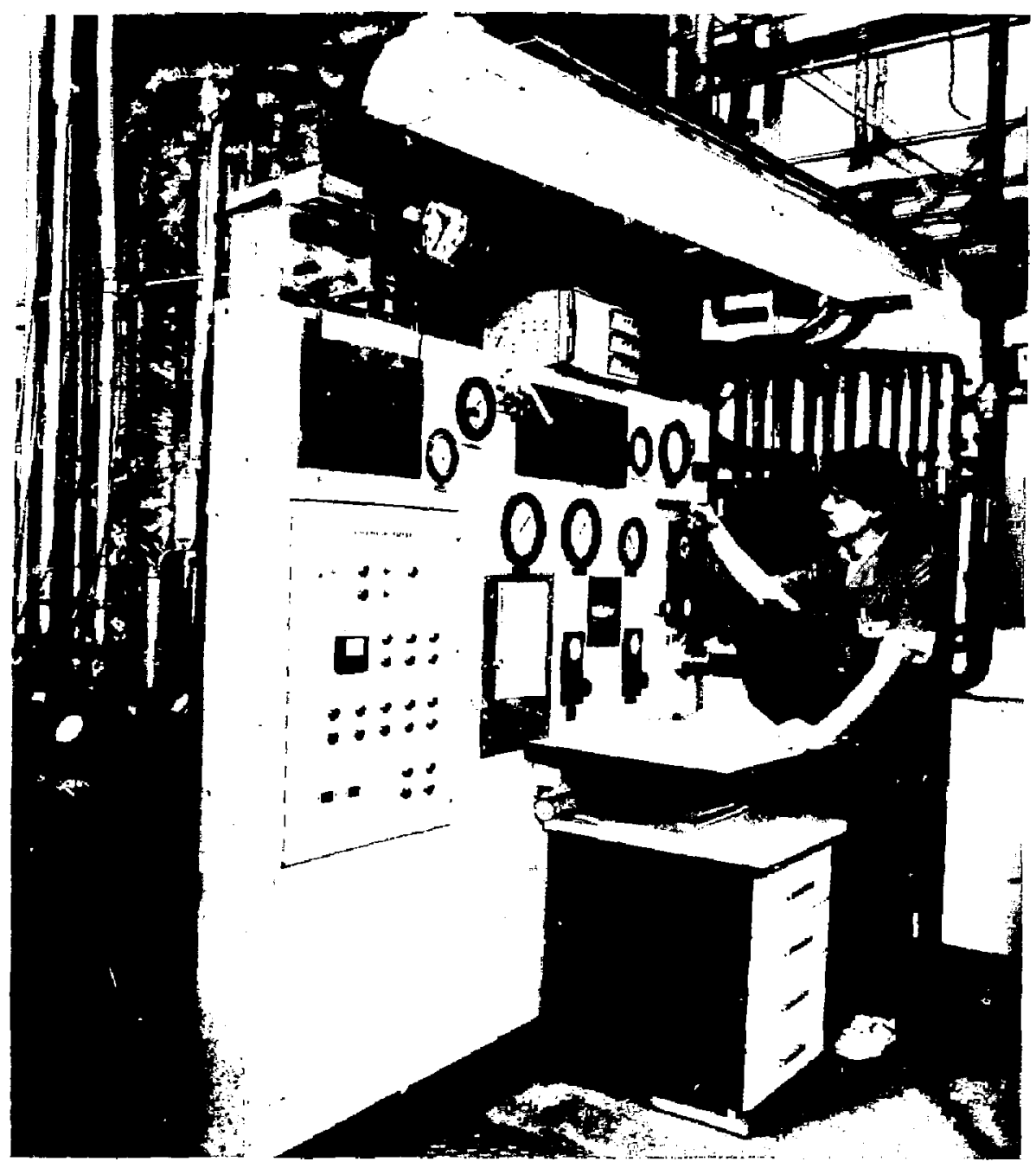

This liquefier, which uses a single turbo expander, has proven performance of over $60 \mathrm{~L} \mathrm{~h}^{-1}$ or $200 \mathrm{~W}$ at $4.5 \mathrm{~K}$. The Airco provides liquid to the HFTF Solenoid. The liquefier can also be put on line to a 10-kL storage dewar, which is used for batch transfer of liquid to the HFTF test well. 


\section{CTI 2800 Helium Liquefier}

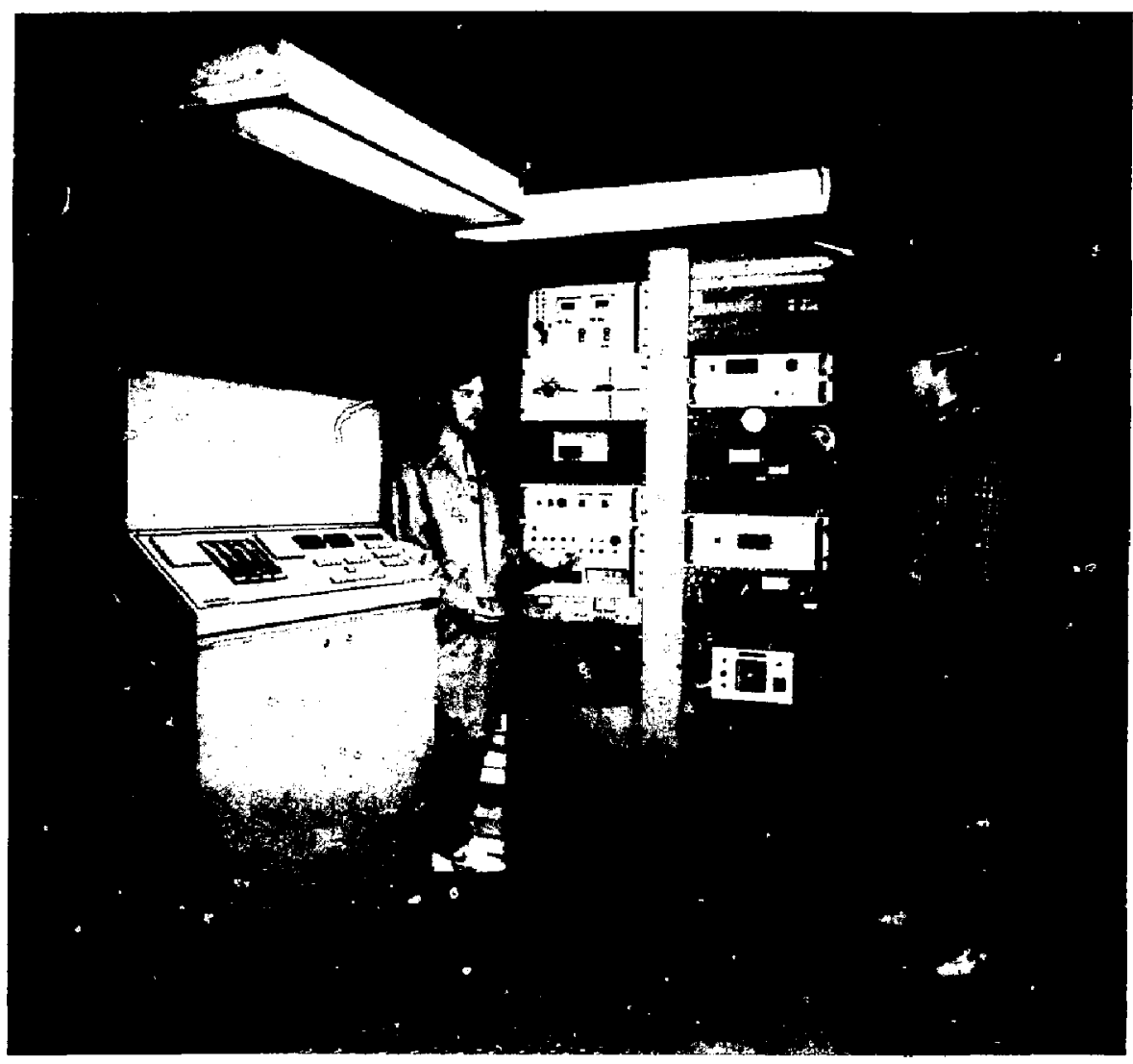

This liquefier has two turbo expanders and two oil-bathed screw compressors for a liquefaction rate of $50 \mathrm{~L} \mathrm{~h}^{-1}$ or approximately $150 \mathrm{~W}$ at $4.5 \mathrm{~K}$. The CTI 2800 is capable of using as many as four compressors for increased performance.

In addition to the Airco and CTI 2800 liquefiers, a CTI 1400 with a make rate of $20 \mathrm{~L} \mathrm{~h}^{-1}$ supports small-scale experiments. Also available are the $3-\mathrm{kW}$ and $8-\mathrm{kW}$ helium liquefiers previously used during testing of the Mirror Fusion Test Facility-B (MFTF-B). 


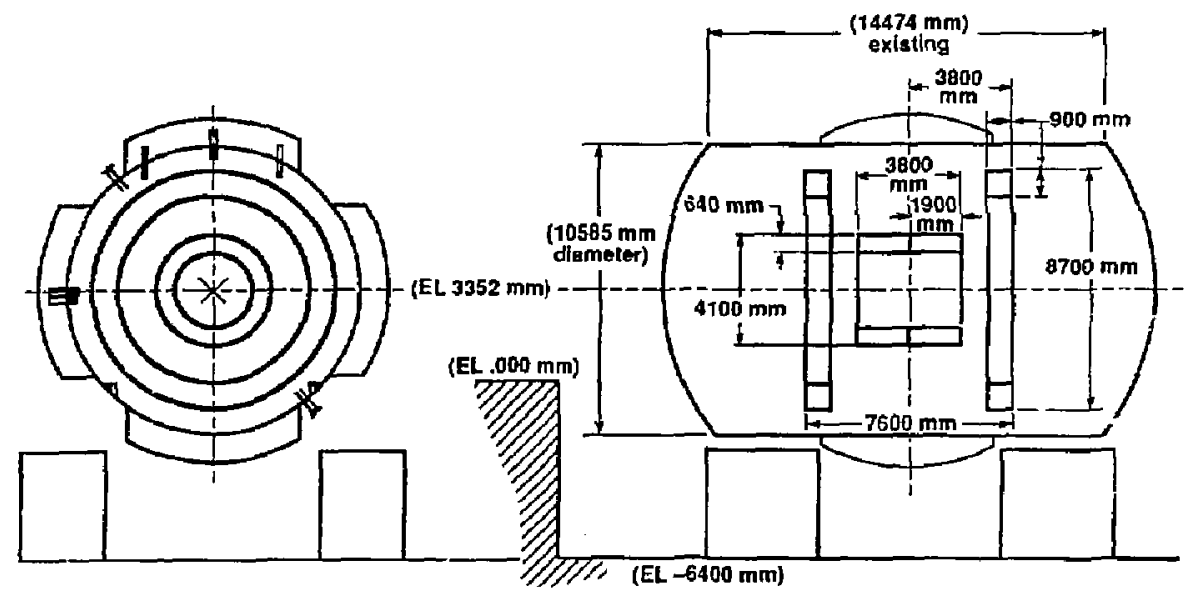

The end cells of the Mirror Fusion Test Facility (MFTF-E) vacuum vessel are shown in a configuration that depicts possible methods of testing full-scale ITER central-solenoid magnets. The MFTF-B end-cell vacuum vessels, cryogenic equipment, power supplies, and other utilities are presently idle and can, in principle, be made available to test extremely large components. 
The superconducting magnet development program at the Lawrence Livermore National Laboratory is a multidisciplinary effort to address engineering and design issues of large magnets. The High-Field Test Facility (HFTF) has a wide range of test capabilities, such as the $2-m$ Solenoid Facility, the FENIX magnet facility, advanced computational capabilities, and cryogenic materials and component testing equipment. Supporting technologies and services are available to meet both large- and small-scale test requirements. HFTF, with its unique test facilities, is fully ready to support ITER magnet development and to assist with international collaborative research. 